\title{
POLYCHLORINATED BIPHENYL SORPTION TO ACTIVATED CARBON AND THE ATTENUATION CAUSED BY SEDIMENT
}

\author{
S.E. HALE ${ }^{1}$ \\ S. KWON ${ }^{2}$ \\ U. $\mathrm{GHOSH}^{2}$ \\ D. WERNER ${ }^{1, *}$
}

Received: 22/04/10

Accepted: 08/09/10

\author{
${ }^{1}$ School of Civil Engineering and Geosciences \\ Newcastle University, Newcastle upon Tyne, NE1 7RU, UK \\ ${ }^{2}$ Department of Civil and Environmental Engineering \\ University of Maryland Baltimore County, Maryland 21250, USA
}

*to whom all correspondence should be addressed: e-mail: david.werner@ncl.ac.uk

\section{ABSTRACT}

Activated carbon $(A C)$ is currently being used to treat polychlorinated biphenyl $(P C B)$ contaminated field sediment. In the presence of sediment, the sorption capacity of AC for PCBs can be reduced. In this study, sorption attenuation of $A C$ is investigated using previously published data from 5 sampling sites where reductions in aqueous concentrations caused by $A C$ amendment have been reported. AC-water partitioning coefficients ( $\left.\mathrm{K}_{\mathrm{AC} \text { _clean_water }}\right)$ were determined at a relevant $\mathrm{PCB}$ concentration in clean water using polyoxymethylene (POM) passive samplers. Logarithmic ACwater partitioning coefficient values ranged from 7.39 to 9.59 for trichlorinated to pentachlorinated congeners. These AC-water partitioning coefficients were used in a numerical model to predict expected reductions in aqueous concentrations. Results reveal an overprediction of actual reductions by a median factor ranging from 2.5 to 5.6. To obtain an estimate of AC sorption attenuation, an AC-water partitioning coefficient more representative of sediment conditions $\left(\mathrm{K}_{\mathrm{AC} \_ \text {apparent }}\right)$ was fitted via the model based on the observed reductions in aqueous concentrations. On average, median $\mathrm{K}_{\mathrm{AC} \_ \text {apparent }}$ values of individual $\mathrm{PCB}$ congeners were smaller than $\mathrm{K}_{\mathrm{AC} \_ \text {clean_water }}$ values by 1.08 log units, or a factor of 12 , with corrections ranging from 0.1 to 2.3 log units. The main controls on the reduction in sorption of PCBs to AC are PCB physico-chemical properties and $A C$ amendment variables. Generally AC sorption attenuation increased with PCB hydrophobicity and decreased with increasing $\mathrm{AC}$-sediment contact time and $\mathrm{AC}$ dose.

KEY WORDS: PCB, activated carbon-water partitioning coefficient, passive sampling, sorption, activated carbon fouling, polyoxymethylene, sediment remediation.

\section{INTRODUCTION}

Following successful laboratory experiments, activated carbon (AC) is currently being used in the field to remediate polychlorinated biphenyl (PCB) contaminated sediment (Cho et al., 2007; 2009). When added to contaminated sediment, $A C$ induces a mass transfer of pollutants from the sediment matrix to itself and reduces contaminant bioavailability. During laboratory experiments, Zimmerman et al. (2004) found that sediment treated with AC resulted in free aqueous PCB concentrations 85 and $92 \%$ lower than those in untreated sediment following one and six-month AC-sediment contact. The addition of $3.4 \%$ AC by dry sediment weight resulted in reductions in total PCB bioaccumulation of $70 \%$ for Leptocheirus amphipods and $82 \%$ for Neanthes worms after 1 month contact time (Millward et al., 2005). AC has a high sorption capacity for PCBs, indicated by large AC-water partitioning coefficients measured in clean water systems (Jonker and Koelmans, 2002). However, this strong organic sorptivity in clean water can be reduced when sediment is added to the system as $A C$ can be fouled by dissolved organic matter and other anthropogenic compounds, resulting in attenuation of the target pollutants' access to AC sorption sites (McDonough et al., 2008; Pignatello, et al., 2006). Two mechanisms of competitive sorption have been proposed; direct site competition and pore blockage, where the mechanism operating depends among other factors, on the relative size of the target pollutant and competing molecules. Previously, the reduction in sorption capacity of 
$A C$ has been shown to be affected by parameters such as AC dose, particle size, AC-sediment treatment time (Hale et al., 2009), sediment physicochemical properties (Cornelissen, et al., 2006), the quantity of possible competing molecules (Brandli et al., 2008) and the aqueous concentration of the target compound (Koelmans et al., 2009).

Methods used to quantify the degree of $A C$ sorption attenuation include: making a comparison of measured free aqueous contaminant concentrations in AC-sediment systems, to those calculated assuming additive sorption to a pure AC and sediment phase (Brandli, et al., 2008; Cornelissen et al., 2006) and a comparison of pollutant concentrations on a virgin $A C$ and the same material after contact with dissolved organic matter (McDonough et al., 2008). In addition, a numerical pollutant mass transfer model has been utilised to predict temporal changes in aqueous and passive sampling device DDT and PCB concentrations expected in AC amended sediments (Hale et al., 2009; Werner et al., 2006) and the results have been compared to experimental measurements. To assess AC sorption attenuation in those cases, the AC-water partitioning coefficients determined in clean water were adjusted until a match with experimental data was obtained and the resulting AC-water partitioning coefficient was considered more representative of a sediment system.

Here we apply the latter kinetic modelling approach (Werner et al., 2006) to study the attenuation of AC sorption capacity in a larger variety of PCB contaminated sediment systems. This kinetic modelling approach is required because aqueous pollutant concentrations continued to decrease over a time period of up to 18 months in the studied sediments, which indicates non-equilibrium and a continuing slow mass transfer of pollutants to the added sorbents. AC particle size effects are also evident and indicative of non-equilibrium. In this study AC-water partitioning coefficients ( $\left.\mathrm{K}_{\mathrm{AC} \_ \text {clean_water }}\right)$ are determined in clean water using polyoxymethylene passive samplers and then AC-water partitioning coefficients more representative of sediment systems ( $\mathrm{K}_{\mathrm{AC}}$ apparent $)$ are obtained via fitting of the corresponding model parameter from the previously reported $\bar{A} \mathrm{C}$-sediment contact experiments. The attenuation of AC sorption capacity for PCBs is discussed based on a comparison of these values.

\section{MATERIALS AND METHODS}

Polyoxymethylene-water partitioning coefficients ( $\left.\mathrm{K}_{\mathrm{POM}-76}\right)$

Sorption of PCBs to polyoxymethylene (POM) was determined in order to calibrate these passive sampling devices and enable accurate determination of aqueous concentrations in systems with an added AC phase. To do this, POM sorption isotherms at four different PCB concentrations were determined. Distilled water $(40 \mathrm{~mL})$, sodium azide $\left(100 \mathrm{mg} \mathrm{L}^{-1}\right)$, and a $25 \mathrm{mg}$ piece of $76 \mu \mathrm{m}$ thick POM (CS Hyde Company, IL, USA) were added to $40 \mathrm{~mL}$ vials with Teflon lined caps. Before use, POM samplers were cleaned via an ultrasonic extraction using $50 \%$ acetone in hexane, after which they were dried in air for 12 hours. A PCB Aroclor 1242 (Supelco, Bellefonte, PA, USA) stock solution in methanol $\left(1000 \mu \mathrm{g} \mathrm{mL}^{-1}\right)$ was used to add between 0.6 and $60 \mu \mathrm{g}$ of PCBs to quadruplicate vials at four concentration levels of the stock solution. Vials were horizontally shaken at $32 \mathrm{rpm}$ on an orbital shaker (Bellco biotechnology, Vineland NJ, USA) for six months in the dark to ensure that the system reached equilibrium (Jonker and Koelmans, 2001, McDonough et al., 2008). At the end of the contact period, POM and water samples were removed, extracted, and PCBs were quantified as described below.

The measured POM-76 and water concentrations determined at each spiking level were used to quantify the polyoxymethylene-water partitioning coefficients $\mathrm{K}_{\mathrm{POM}-76}\left(\mathrm{~cm}^{3} \mathrm{~g}^{-1}\right)$ according to equation (1)

$K_{P O M-76}=\frac{C_{P O M-76}}{C_{W}}$

where $C_{P O M}\left(\mathrm{~g} \mathrm{~g}^{-1}\right)$ is the concentration in the POM sampler and $C_{W}\left(\mathrm{~g} \mathrm{~cm}^{-3}\right)$ is the aqueous concentration.

\section{PCB sorption to activated carbon in clean water}

Sorption to $A C$ was characterised by measuring the $A C$-water partitioning coefficient ( $\mathrm{K}_{\mathrm{AC}}$ clean water $)$ in clean water at a single PCB concentration. $10 \mathrm{mg}$ of bituminous coal based $\mathrm{AC}$, with a particle size range of 44-177 $\mu \mathrm{m}$ (TOG, Calgon Carbon Co, Pittsburgh, PA, USA), deionised water (40 mL), sodium azide $\left(100 \mathrm{mg} \mathrm{L}^{-1}\right)$ and a POM-76 passive sampler $(0.5 \mathrm{~g})$ were added to quadruplicate vials with Teflon lined lids. Vials were spiked with $20 \mu \mathrm{g}$ PCBs using the Aroclor 1242 stock solution in 
methanol, to ensure the analytical limit of detection was exceeded assuming a $99 \%$ transfer of PCBs to $A C$. In addition, quadruplicate batches without $A C$ were used as the reference system. All vials were mixed at $32 \mathrm{rpm}$ in the dark for six months, after which POM-76 sheets were analysed as described below. Individual PCB congener mass balances for the reference systems ranged from 88 to $113 \%$. To determine the AC-water partitioning coefficient $\left(\mathrm{K}_{\mathrm{AC}} \mathrm{cm}^{3} \mathrm{~g}^{-1}\right)$, a three phase closed system mass balance was constructed for each PCB congener following the method described by McDonough et al. (2008) and $\mathrm{K}_{\mathrm{AC}}$ was calculated according to equation (2):

$K_{A C}=\frac{C_{A C}}{C_{W}}$

where $C_{A C}$ is the PCB concentration on the $A C\left(g^{-1}\right)$. Aqueous PCB equilibrium concentrations determined for batches containing $A C$ that accompany measured $K_{A C}$ values ranged from $0.61 \mathrm{ng} \mathrm{L}^{-1}$ (PCB 18) to $0.0023 \mathrm{ng} \mathrm{L}^{-1}$ (PCB 99).

\section{Sample extraction}

After the equilibration periods, POM-76 samplers were removed from vials, rinsed, cleaned with a tissue and dried, then extracted for two days in $12 \mathrm{~mL}$ of hexane followed by nine days in $12 \mathrm{~mL}$ of $50 \%$ acetone in hexane. An additional 16 hour soxhlet extraction with $50 \%$ acetone in hexane revealed less than $1 \%$ of individual PCB congeners remained in the POM-76. Prior to hexane extraction of POM-76, surrogate standards of 3,5-dichlorobiphenyl (PCB 14), 2,3,5,6tetrachlorobiphenyl (PCB 65) and 2,2',3,3',4,5',6-heptachlorobiphenyl (PCB 175) were added to monitor processing recovery. Extracts were combined and solvent exchanged to hexane before PCB quantification. The water phase in experiments to determine $\mathrm{K}_{\mathrm{POM}-76}$ was also extracted three times with hexane and samples prepared for analysis in an analogous fashion.

\section{PCB quantification}

PCB determination was carried out using a modified USEPA method 8082A as described in Sun and Ghosh (2008). Analysis was performed on an Aligent 6890N gas chromatograph (Restek, Bellefonte, PA, USA) with an electron capture detector and a fused silica capillary column (Rtx-5MS, $60 \mathrm{~m} \mathrm{x}$ $0.25 \mathrm{~mm}$ i.d, $0.25 \mu \mathrm{m}$ film thickness). PCB standards for calibration were purchased as hexane solutions (Ultra Scientific NorthKingstown, RI, USA). A multi-level calibration table was prepared using a PCB mixture containing $250 \mu \mathrm{g} \mathrm{L}^{-1}$ of Aroclor 1232, $180 \mu \mathrm{g} \mathrm{L}^{-1}$ of Aroclor 1248 and $180 \mu \mathrm{g} \mathrm{L}^{-1}$ of Aroclor 1262. Before quantification of PCBs, 2,4,6-trichlorobiphenyl (PCB 30) and 2,2',3,4,4',5,6,6'octachlorobiphenyl (PCB 204) were added to all samples as internal standards.

\section{Estimating PCB-sorption to $A C$ in sediments}

$\mathrm{K}_{\mathrm{AC}}$ apparent values were obtained using previously published experimental data (Sun and Ghosh, 2008; Werner et al., 2005; Zimmerman et al., 2004; Zimmerman et al., 2005) and a numerical mass transfer model (Werner et al., 2006) which predicts the reduction in free aqueous concentration in sediments amended with AC. The numerical model expresses the uptake and release of pollutants by sediment and AC particles and accounts for slow intraparticle diffusion kinetics. It considers the effect of the sediment characteristics, the AC dose and particle size and the AC-sediment contact time. The desorption of pollutants from sediments was modeled using a two compartment diffusive release model (Werner et al., 2006). AC-water partitioning coefficients representative of sediment conditions $\left(\mathrm{K}_{\mathrm{AC} \_ \text {apparent }}\right)$ were derived by adjusting the $\mathrm{K}_{\mathrm{AC} \_ \text {clean_water }}$ parameter value in the model until predicted ratios of aqueous concentrations measured in untreated sediment relative to $A C$ amended sediment fitted the experimentally measured values. Data were modeled for a variety of AC doses and AC-sediment contact times using type TOG AC with a particle size 75-300 $\mu \mathrm{m}$ (Calgon Corporation, Pittsburg, PA). The previous experimental data were collected for sediments at Milwaukee River for two different sampling sites (MR1 and MR2), Grasse River (GR), Hunters Point (HP) and Lake Hartwell (LH), all in the USA. The AC amendment variables were as follows; MR1contact time 1 month at $A C$ doses $0.6,1.6$ and $3.2 \%$ and contact time 6 months at $A C$ dose $1.6 \%$. MR2-contact time 1 month at $A C$ doses $0.74,1.8$ and $3.7 \%$ and contact time 6 months at $A C$ dose 1.8\%. GR-contact time 1 month at $A C$ doses 1 and $2.6 \%$ and contact time 6 months at $A C$ dose $2.6 \%$. HP-contact time 1 month at AC doses $0.34,1.7$ and $3.4 \%$ and contact time 6 months at $A C$ dose $3.4 \%$. LH-contact time 1 month at AC dose $2 \%$. Details of the experimental methods and 
further description of the results can be found elsewhere (Sun and Ghosh, 2008; Werner et al., 2005; Zimmerman et al., 2004; 2005).

\section{RESULTS AND DISCUSSION}

Polyoxymethylene-water partitioning coefficients (K

$\mathrm{K}_{\mathrm{POM}-76}$ values were determined over four $\mathrm{PCB}$ spiking concentrations in order to quantify aqueous PCB concentrations in batches containing an additional $A C$ phase and hence allow AC-water partitioning coefficients to be obtained. The isotherms were linear and so an overall log $\mathrm{K}_{\mathrm{POM}-76}$ value for each congener was obtained by considering the average log $\mathrm{K}_{\mathrm{POM}-76}$ at each spiking level as an individual replicate and taking the average of all values. This method has previously been identified as preferable to taking the slope of the nonlogarithmic isotherm to prevent dominance of higher concentrations (Jonker and Koelmans, 2001). The values determined are shown in Table 1 and are compared to literature values for data sets using different thickness POM samplers (Cornelissen et al., 2008; Hawthorne et al., 2009; Jonker and Koelmans, 2001; McDonough et al., 2008). Values agree mostly within a factor of 3 or \pm 0.5 log units to those determined by Hawthorne et al. (2009), who use a very different solid phase microextraction based method to calibrate the same POM-76 samplers. Values reported by Cornelissen et al. (2008) who use a $55 \mu \mathrm{m}$ thick sampler agree within \pm 0.4 log units. This discrepancy may have resulted from differences in analytical methodologies, as the $\mathrm{K}_{\mathrm{POM}-55}$ values of Cornelissen et al. (2008) were determined in a methanol:water system, rather than a clean water system. $\mathrm{K}_{\mathrm{POM}-76}$ values are approximately 1 log unit larger than those reported by Jonker and Koelmans (2001) and McDonough et al. (2008) who employed $500 \mu \mathrm{m}$ thick samplers. The almost 10 fold difference in POM thickness could cause different sampler physicalchemical/structural properties which may have a significant impact on PCB sorption.

Table 1. Average log $\mathrm{K}_{\mathrm{POM}}\left(\mathrm{cm}^{3} \mathrm{~g}^{-1}\right)$ values for individual PCBs with a comparison to previously reported data. Values shown in parenthesis are the standard deviation of four replicates.

\begin{tabular}{|c|c|c|c|c|c|}
\hline \multirow{2}{*}{$\begin{array}{l}\text { IUPAC } \\
\text { congener } \\
\text { number }\end{array}$} & \multirow{2}{*}{$\begin{array}{l}\text { Measured } \\
\text { Log K } \mathrm{P}_{\mathrm{POM}} \\
\text { POM-76 }\end{array}$} & \multicolumn{4}{|c|}{ Literature Log К Ком } \\
\hline & & POM-76 ${ }^{\mathrm{a}}$ & POM-55 $5^{b}$ & POM-500 ${ }^{\mathrm{C}}$ & POM-500 ${ }^{d}$ \\
\hline 18 & $5.06( \pm 0.08)$ & $5.12( \pm 0.05)$ & $4.83( \pm 0.04)$ & $3.90( \pm 0.05)$ & $3.84( \pm 0.13)$ \\
\hline 19 & $4.63( \pm 0.30)$ & & & & \\
\hline 22 & $5.34( \pm 0.05)$ & $5.40( \pm 0.06)$ & & & \\
\hline 25 & $5.16( \pm 0.21)^{\mathrm{e}}$ & & & & \\
\hline 26 & $5.23( \pm 0.12)$ & $5.41( \pm 0.01)$ & & & \\
\hline 28 & $5.33( \pm 0.13)$ & $5.68( \pm 0.06)$ & $5.09( \pm 0.08)$ & $4.41( \pm 0.05)$ & \\
\hline 31 & $5.27( \pm 0.12)$ & $5.51( \pm 0.04)$ & & & \\
\hline 40 & $5.81( \pm 0.37)$ & & & & \\
\hline 42 & $5.76( \pm 0.38)$ & $5.64( \pm 0.12)$ & & & \\
\hline 44 & $5.58( \pm 0.16)$ & $5.65( \pm 0.05)$ & & & \\
\hline 45 & $5.69( \pm 0.33)$ & $5.31( \pm 0.03)$ & & & \\
\hline 47 & $6.01( \pm 0.46)$ & $5.59( \pm 0.13)$ & & & \\
\hline 51 & $5.32( \pm 0.19)$ & & & & \\
\hline 64 & $5.62( \pm 0.15)$ & $5.80( \pm 0.02)$ & & & \\
\hline 74 & $5.90( \pm 0.23)$ & $6.13( \pm 0.06)$ & & & \\
\hline 83 & $5.82( \pm 0.89)^{e}$ & & & & \\
\hline 91 & $5.32( \pm 0.34)^{\mathrm{e}}$ & & & & \\
\hline 97 & $5.93^{\mathrm{e}}$ & $6.23( \pm 0.18)$ & & & \\
\hline 99 & $6.78( \pm 0.47)^{\mathrm{e}}$ & $6.17( \pm 0.04)$ & & & \\
\hline 101 & $6.32^{\mathrm{e}}$ & $5.90( \pm 0.04)$ & $5.93( \pm 0.14)$ & $4.91( \pm 0.10)$ & \\
\hline 118 & $6.24^{\mathrm{e}}$ & $6.32( \pm 0.14)$ & $6.32( \pm 0.13)$ & $5.05( \pm 0.08)$ & \\
\hline \multirow{2}{*}{\multicolumn{3}{|c|}{$\begin{array}{l}\text { a Data taken from Hawthorne et al. (2009) } \\
{ }^{2} \text { Data taken from Jonker and Koelmans (2001) }\end{array}$}} & \multicolumn{3}{|c|}{ Data taken from Cornelissen et al. (2008) } \\
\hline & & & ${ }^{\mathrm{d}}$ Data take & from McDonous & et al. (2008) \\
\hline
\end{tabular}




\section{PCB sorption to AC}

AC-water partitioning coefficients measured in clean water ( $\left.\mathrm{K}_{\mathrm{AC} \_ \text {clean_water }}\right)$ for $\mathrm{AC}$ type $\mathrm{TOG}$ at a single $\mathrm{PCB}$ concentration point in the pico to nanogram per liter aqueous $\mathrm{PCB}$ concentration range are shown in Table 2. These $\mathrm{K}_{\mathrm{AC} \text { _clean_water values agree well with those determined in an analogous }}$ fashion with calibrated POM-500 samplers for a few congeners (Jonker and Koelmans, 2002) and those derived from sorption isotherms (McDonough et al., 2008), despite the differences in $\mathrm{K}_{\mathrm{POM}-76}$ and $\mathrm{K}_{\mathrm{POM}-500}$ values discussed in the previous section. This agreement highlights the importance of calibrating the passive sampler (in this case by determining partitioning coefficients) being used in experimental work before being able to accurately determine free aqueous concentrations and subsequent sorbent-water partitioning. While Jonker and Koelmans (2002) use a peat based AC, McDonough et al. (2008) use the same AC type as is used here. Differences in AC physical properties could contribute to the small differences in AC-water partitioning coefficients reported. Logarithmic $\mathrm{K}_{\mathrm{AC} \_ \text {clean_water }}$ values range from 7.39 to 9.59 for tri- tetra- and penta-chlorinated PCBs demonstrating the very strong adsorption of these compounds to AC. The sorption of planar PCBs has been noted to be stronger than the sorption of similarly sized non planar PCBs (Bucheli and Gustafsson, 2003) and a similar phenomenon may be occurring for this data. However the small size of the data set makes it difficult to draw sound conclusions related to the effect of congener planarity.

Table 2. Measured aqueous PCB concentrations as well as average log $\mathrm{K}_{\mathrm{AC}}\left(\mathrm{cm}^{3} \mathrm{~g}^{-1}\right)$ values for individual $\mathrm{PCBs}$ with a comparison to previously reported data and log $\mathrm{K}_{\mathrm{AC} \_ \text {apparent }}$ values modeled in a sediment system. Values shown in parenthesis are the standard deviation of quadruplicate replicates

\begin{tabular}{|c|c|c|c|c|c|}
\hline \multirow{2}{*}{$\begin{array}{l}\text { IUPAC } \\
\text { congener } \\
\text { number }\end{array}$} & \multirow{2}{*}{$\begin{array}{l}\text { Aqueous PCB } \\
\text { concentration } \\
\left(\text { ng L L }^{-1}\right)\end{array}$} & \multicolumn{2}{|c|}{$\begin{array}{c}\text { Log } \mathrm{K}_{\mathrm{AC}} \\
\text { Clean water }\end{array}$} & \multicolumn{2}{|c|}{$\begin{array}{l}\text { Log } \mathrm{K}_{\mathrm{AC} \text { _apparent }} \\
\text { Sediment }\end{array}$} \\
\hline & & Measured & Literature & Range $^{c}$ & Median \\
\hline 18 & 0.61 & $8.21( \pm 0.04)$ & $8.13^{a}, 8.16^{b}$ & $6.41-8.48$ & 7.89 \\
\hline 19 & 0.39 & $7.39( \pm 0.08)$ & & $6.79-7.60$ & 7.30 \\
\hline 22 & 0.34 & 8.22 & & $6.50-8.27$ & 7.83 \\
\hline 25 & 0.043 & $8.42( \pm 0.02)$ & & $7.55-8.20$ & 7.86 \\
\hline 26 & 0.064 & $8.40( \pm 0.03)$ & & $6.72-8.03$ & 7.66 \\
\hline 28 & 0.037 & $8.47( \pm 0.03)$ & $8.44^{b}$ & $7.00-8.47$ & 8.08 \\
\hline 31 & 0.46 & $8.41( \pm 0.06)$ & & $7.13-7.91$ & 7.63 \\
\hline 40 & 0.030 & $8.77( \pm 0.02)$ & & $6.91-8.53$ & 7.27 \\
\hline 42 & 0.043 & $8.99( \pm 0.44)$ & & $6.83-8.24$ & 7.33 \\
\hline 44 & 0.18 & $8.54( \pm 0.03)$ & & $6.18-7.08$ & 6.99 \\
\hline 45 & 0.058 & $8.70( \pm 0.44)$ & & $6.24-9.78$ & 7.15 \\
\hline 47 & 0.021 & $8.91( \pm 0.07)$ & & $6.11-8.91$ & 7.44 \\
\hline 51 & 0.040 & $8.06( \pm 0.19)$ & & $6.69-9.08$ & 6.96 \\
\hline 64 & 0.068 & $8.61( \pm 0.06)$ & & $6.79-8.70$ & 7.15 \\
\hline 74 & 0.039 & $8.87( \pm 0.04)$ & & $6.52-9.01$ & 7.47 \\
\hline 83 & 0.00043 & 8.64 & & $6.89-9.47$ & 7.05 \\
\hline 91 & 0.045 & $8.08( \pm 0.01)$ & & $6.65-8.34$ & 7.78 \\
\hline 97 & 0.012 & 8.58 & & $6.12-9.73$ & 7.17 \\
\hline 99 & 0.0023 & $9.59( \pm 0.06)$ & & $6.47-9.59$ & 7.74 \\
\hline 101 & 0.010 & 9.05 & $9.18^{b}$ & $6.64-9.23$ & 7.74 \\
\hline 118 & 0.012 & $9.01( \pm 0.05)$ & $9.45^{b}$ & $6.06-9.01$ & 7.69 \\
\hline
\end{tabular}

${ }^{a}$ Values calculated (interpolated) at $1 \mathrm{ng} \mathrm{L}^{-1}$ aqueous concentration using reported Freundlich isotherm parameters (McDonough et al., 2008)

${ }^{\mathrm{b}}$ Data taken from Jonker and Koelmans (2002)

${ }^{\mathrm{C}}$ Fitted log $\mathrm{K}_{\mathrm{AC} \_ \text {apparent }}$ values represent the upper and lower limit across all contaminated sites and their AC treatment variables.

\section{Activated carbon sorption attenuation in sediment systems}

The $\mathrm{K}_{\mathrm{AC} \_ \text {clean_water }}$ values were used to predict the thermodynamic equilibrium aqueous concentrations after AC amendment of Lake Hartwell (LH), Hunters Point (HP), Grasse River (GR) and Milwaukee River sites 1 (MR1) and 2 (MR2) sediments based on the assumption that the 


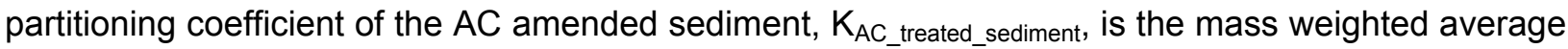
of the sediment-water partitioning coefficient, $\mathrm{K}_{\mathrm{d} \text {,sed }}$, and the $\mathrm{K}_{\mathrm{AC} \_ \text {clean_water }}$ values according to

$$
K_{\text {AC_rreated_sediment }}=(1-d o s e) \cdot K_{\text {d,sed }}+\text { dose } \cdot K_{\text {AC_clean_water }}
$$

where dose is the amount of $A C$ added to the sediment $\left(\mathrm{g} \mathrm{g}^{-1}\right)$.

Figure 1a shows the predicted and measured aqueous $P C B$ concentrations for the $A C$ treated sediments. It is clear that aqueous concentrations are greatly underpredicted. This could be related to the fact that the new sorption equilibrium has not been established during this 6 month experimental timeframe. To investigate such an effect, the $\mathrm{K}_{\mathrm{AC}}$ clean_water values were used in the kinetic mass transfer model to predict the aqueous concentrations obtained in the approach towards the new thermodynamic equilibrium. These predications are compared with the measured aqueous concentrations in Figure 1b. Consideration of the sorption kinetics improves the agreement between measured and predicted values significantly, indicated by the data's closer proximity to the 1:1 line. However, measured aqueous concentrations are still underpredicted and median factors of 5.6, 2.5, 5.0, 4.6 and 3.0 are obtained for LH, HP, GR, MR1 and MR2 sediments respectively. There is considerable scatter in the data in Figure $1 \mathrm{~b}$, partially due to the experimental uncertainty of measuring free aqueous PCB concentrations near analytical detection limits and partially due to simplified model assumptions. However, we believe the systematic underestimation of the free aqueous PCB concentration could be explained by AC sorption attenuation.
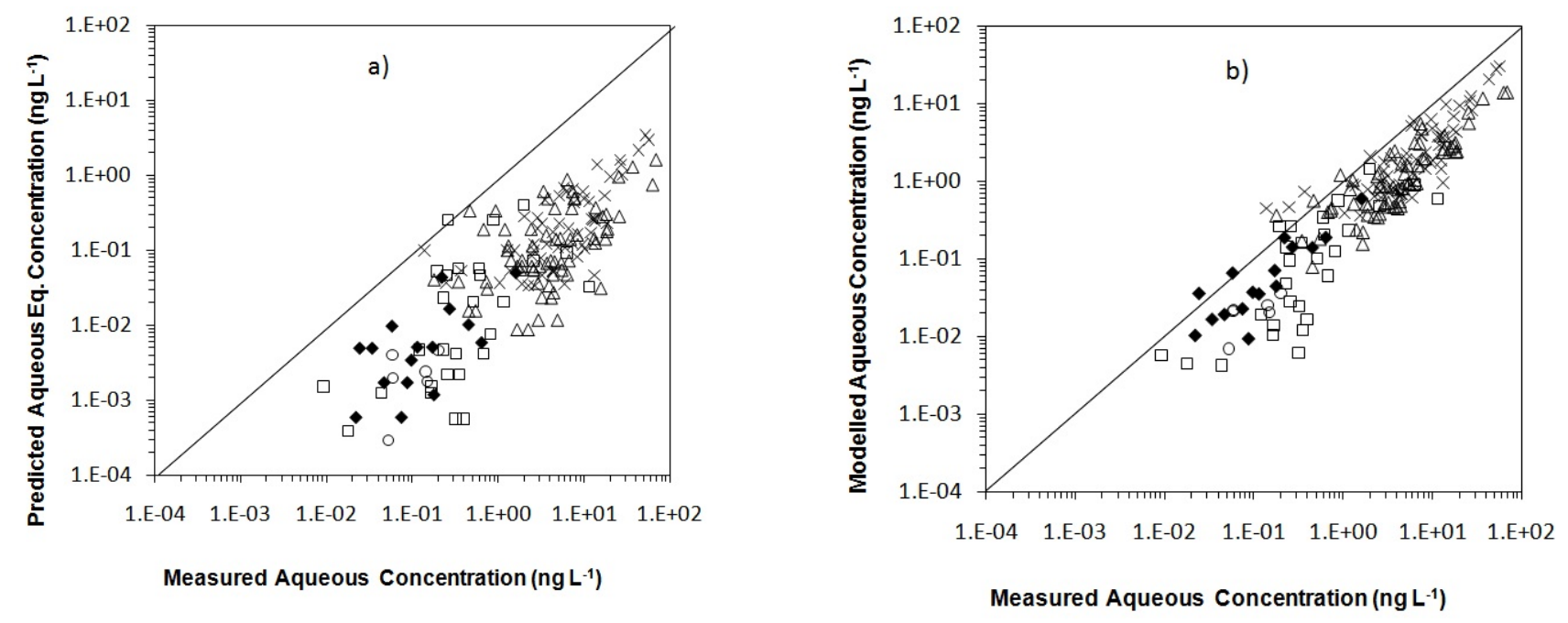

Figure 1. Comparison of measured aqueous PCB concentrations with those predicted (using $\mathrm{K}_{\mathrm{AC} \text { _clean water }}$ ) a) by assuming thermodynamic equilibrium and b) by employing the mass transfer model. Data represent Hunters Point ( $\bullet$ ), Lake Hartwell (०), Grasse River (๑), Milwaukee River location $1(\Delta)$ and Milwaukee River location $2(x)$ sediments.

Previously, Werner et al. (2006) used four PCB congener $\mathrm{K}_{\mathrm{AC} \text { _clean water }}$ values taken from Jonker and Koelmans (2002) in the same model and concluded that reducing the values by a constant factor of 16 could account for the reduced AC sorption strength caused by the presence of sediment. This reduction is most likely caused by dissolved organic matter contained in the sediment which inhibits the uptake of PCBs by AC (Hale et al., 2009; McDonough et al., 2008). To obtain AC-water partitioning coefficients more representative of sediment conditions, the $\mathrm{K}_{\mathrm{AC} \text { _clean_water }}$ model input parameter value was adjusted to fit the experimental data and the resulting partitioning coefficient was termed $\mathrm{K}_{\mathrm{AC} \_ \text {apparent. }}$ Table 2 shows that individual PCB congener $\mathrm{K}_{\mathrm{AC} \text { _apparent }}$ values can vary by three log units for experiments conducted with different sediments, AC doses and AC-sediment contact times. However, all median values of $\log \mathrm{K}_{\mathrm{AC}}$ apparent for individual $\mathrm{PCBs}$ are smaller than log

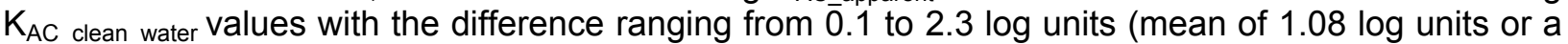
factor of 12). This result is expected when invoking the notion of AC sorption attenuation. A reduction in the model $\mathrm{K}_{\mathrm{AC} \text { _clean_water }}$ parameter value will reduce the $\mathrm{AC}$ sorbent strength for aqueous PCBs, but will also allow faster uptake since AC sorption kinetics are modelled based on sorption-retarded intraparticle diffusion. Therefore, to explain a median factor 2.5 to 5.6 underprediction of the measured reduction in aqueous PCB concentrations during the time period 
required to achieve $A C$ sorption equilibrium, which may take up to several years, the log $\mathrm{K}_{\mathrm{AC} \_ \text {clean_water }}$ values needed to be adjusted by about $1 \mathrm{log}$ unit to explain the observed discrepancy between the measured and modelled aqueous PCB concentrations.

\section{Factors affecting $A C$ sorption attenuation in sediment}

The factors affecting $A C$ sorption attenuation were investigated by correlating $A C$ attenuation factors with treatment (PCB congener or $A C$ ) variables. The $A C$ attenuation factor was obtained by comparing the clean water $\mathrm{K}_{\mathrm{AC}}$ with the representative sediment $\mathrm{K}_{\mathrm{AC}}$ according to $\mathrm{K}_{\mathrm{AC} \text { _clean_water }} / \mathrm{K}_{\mathrm{AC} \text { apparent. }} \mathrm{A}$ statistically significant correlation (Spearmans Rank test, $\mathrm{p}<0.05$ ) between $A C$ attenuation factors and PCB congener hydrophobicity (represented by $K_{\text {ow }}$ ) for GR, MR1 and MR2 sediments was obtained. Previously Pignatello et al. (2006) noted that the attenuation of hydrophobic organic compound sorption to charcoal with added humic substances also increased with compound hydrophobicity.

For DDT contaminated sediment, it was observed that attenuation factors decrease with increasing AC dose (Hale et al., 2009). For these PCB-contaminated sediments this trends is not so readily apparent. Increasing the AC dose decreased the median attenuation factor observed after 1 month for HP sediment, but the opposite effect was seen for MR2 sediment.

\section{Potential impact of sediment on AC sorption kinetics}

For DDT contaminated sediment, attenuation factors also decreased with increasing AC-sediment contact time (Hale et al., 2009). This phenomenon could not be explained by the AC sorption attenuation mechanism assumed by the numerical model which is direct competition for sorption sites. Instead, it indicates AC pore blockage or coating of AC surfaces with organic matter deposits which result in slower diffusion of PCBs and consequently retards the AC sorption of PCBs in the short term but not in the longer term (Hale et al., 2009). For the PCB-contaminated sediments the median attenuation factors after 1 and 6 months (GR: 24 at 1 month and 26 at 6 months, MR1: 30 at 1 month and 34 at 6 months, MR2: 27 at 1 month and 19 at 6 months, HP: 19 at 1 month and 14 at 6 months) were not statistically significantly different (Mann Whitney $U$ test, $p<0.05$ ) for any of the sediments. However, a statistically significant correlation (Mann Whitney $U$ test, $p<0.05$ ) was obtained for LH sediment contacted with $2 \%$ AC for up to 18 months (Werner, et al., 2005) when modeled and measured PCB concentrations in semipermeable membrane devices were considered. Median attenuation factors were 6,5 and 1 for 1,6 and 18 months contact time. Thus at 18 months, the $A C$ in this sediment apparently performed similarly to $A C$ in clean water. A similar conclusion cannot be drawn for the measured and modelled aqueous concentrations as data were only obtained for a 1 month contact with LH sediment.

\section{The potential impact of AC sorption nonlinearity}

The numerical model uses a constant parameter value for $\mathrm{K}_{\mathrm{AC}}$ clean_water or $\mathrm{K}_{\mathrm{AC}}$ apparent and thus neglects an eventual nonlinearity of the $A C$ sorption isotherm. This could potentially explain the underestimation of the aqueous PCB concentration in AC amended sediment from MR1 and MR2 sites. In those sediments, aqueous PCB concentrations were higher in experimental samples than those for which the $\mathrm{K}_{\mathrm{AC}}$ clean_water values were determined at Table 2. However, aqueous PCB concentrations in HP, $\mathrm{LH}$ and $\mathrm{GR}$ sediments were also underestimated, despite aqueous concentrations being in a similar range to those used when determining $\mathrm{K}_{\mathrm{AC}}$ clean_water. This suggests that $A C$ sorption nonlinearity cannot explain the systematic underestimation of all data in Figure 1. The nonlinearity of the PCB sorption to AC is not as strong for low aqueous concentrations such as those considered here, compared to sorption isotherms determined near the aqueous solubility limit (Walters and Luthy, 1984). For instance, the average Freundlich exponent reported for PCB sorption isotherms for clean water, DOM loaded $A C$ and $A C$ with biofilms are fairly close to unity at $0.84,0.91$ and 0.82 (McDonough et al., 2008). In addition, the average Freundlich exponent reported for DDTs sorption to two ACs with DDTs concentrations in the picogram to nanogram per liter concentration range was 0.95 (Hale et al., 2009). It seems unlikely therefore, that nonlinearity of the PCB sorption isotherm could be the main reason for the observed deviation between the aqueous PCB concentrations predicted by the model and the experimental data. More plausible is competitive sorption or pore blocking by other dissolved substances in sediment porewater. 


\section{CONCLUSIONS}

Polyoxymethylene passive samplers were used to determine AC-water partitioning coefficients of PCBs in clean water. These values were compared to apparent AC-water partitioning coefficients (those considered more representative of sediment conditions) measured for a range of PCBimpacted sediments. The comparison indicated that $\mathrm{PCB}$ mass transfer limitations (from sediment to $A C$ ) and sorption attenuation of $A C$ resulted in reduced partitioning coefficients of individual PCB congeners by a factor ranging from 0.1 to $2.3 \mathrm{log}$ units (median of $1.08 \mathrm{log}$ units). Pollutant congener hydrophobicity and AC amendment variables such as dose, grain size and the AC-sediment contact time are potential parameters that can influence the $A C$ sorption attenuation. Despite the reduction in the sorption capacity of the $\mathrm{AC}$ evidenced from this reduction of $\mathrm{AC}$-water partitioning coefficients in the presence of sediment, the remaining $A C$ sorbent strength is still sufficient to greatly reduce aqueous PCB concentrations in all sediments for AC doses in the range of 1 to $3.7 \%$ by dry sediment weight. In addition, time trends in closed batch systems indicate this sorbent strength can be maintained long-term as is evidenced by a continuing decrease of the PCB availability for up to 18 months of AC-sediment contact.

\section{Acknowledgements}

Funding was provided by EPSRC grant EP/D079055/1 and the Leverhulme Trust grant F/00 125/AA. Support for S. Kwon and U. Ghosh was provided by Alcoa and the National Institutes of Health, Superfund Research Program.

\section{REFERENCES}

Brandli R.C., Hartnik T., Henriksen T. and Cornelissen G. (2008) Sorption of native polyaromatic hydrocarbons (PAH) to black carbon and amended activated carbon in soil, Chemosphere, 73(11), 1805-1810.

Bucheli T.D. and Gustafsson O. (2003) Soot sorption of non-ortho and ortho substituted PCBs, Chemosphere, 53, 515-522.

Cho Y.-M., Smithenry D.W., Ghosh U., Kennedy A.J., Millward R.N., Bridges T.S. and Luthy R.G. (2007) Field methods for amending marine sediment with activated carbon and assessing treatment effectiveness, Marine Environmental Research, 64(5), 541-555.

Cho Y.M., Ghosh U., Kennedy A.J., Grossman A., Ray G., Tomaszewski J.E., Smithenry D.W., Bridges T.S. and Luthy R.G. (2009) Field Application of Activated Carbon Amendment for In-Situ Stabilization of Polychlorinated Biphenyls in Marine Sediment, Environ. Sci. Technol., 43(10), 3815-3823.

Cornelissen G., Breedveld G.D., Kalaitzidis S., Christanis K., Kibsgaard A. and Oen A.M.P. (2006) Strong sorption of native PAHs to pyrogenic and unburned carbonaceous geosorbents in sediments, Environ. Sci. Technol., 40(4), 1197-1203.

Cornelissen G., Arp H.P.H., Pettersen A., Hauge A. and Breedveld G.D. (2008) Assessing PAH and PCB emissions from the relocation of harbour sediments using equilibrium passive samplers, Chemosphere, 72(10), 1581-1587.

Hale S.E., Tomaszewski J.E., Luthy R.G. and Werner D. (2009) Sorption of dichlorodiphenyltrichloroethane (DDT) and its metabolites by activated carbon in clean water and sediment slurries, Water Research, 43, 4336-4346.

Hawthorne S.B., Miller D.J. and Grabanski C.B. (2009) Measuring low picogram per liter concentrations of freely dissolved polychlorinated biphenyls in sediment pore water using passive sampling with polyoxymethylene, Analytical Chemistry, 81(22), 9472-9480.

Jonker M.T.O. and Koelmans A.A. (2001) Polyoxymethylene solid phase extraction as a partitioning method for hydrophobic organic chemicals in sediment and soot, Environ. Sci. Technol., 35(18), 3742-3748.

Jonker M.T.O. and Koelmans A.A. (2002) Sorption of polycyclic aromatic hydrocarbons and polychlorinated biphenyls to soot and soot-like materials in the aqueous environment mechanistic considerations, Environ. Sci. Technol., 36(17), 3725-3734.

Koelmans A.A., Meulman B., Meijer T. and Jonker M.T.O. (2009) Attenuation of polychlorinated biphenyl sorption to charcoal by humic acids, Environ. Sci. Technol., 43(3), 736-742.

McDonough K.M., Fairey J.L. and Lowry G.V. (2008) Adsorption of polychlorinated biphenyls to activated carbon: Equilibrium isotherms and a preliminary assessment of the effect of dissolved organic matter and biofilm loadings, Water Research, 42(3), 575-584.

Millward R.N., Bridges T.S., Ghosh U., Zimmerman J.R. and Luthy R.G. (2005) Addition of activated carbon to sediments to reduce PCB bioaccumulation by a polychaete (Neanthes 
arenaceodentata) and an amphipod (Leptocheirus plumulosus), Environ. Sci. Technol., 39(8), 2880-2887.

Pignatello J.J., Kwon S. and Lu Y.F. (2006) Effect of natural organic substances on the surface and adsorptive properties of environmental black carbon (char): Attenuation of surface activity by humic and fulvic acids, Environ. Sci. Technol,. 40(24), 7757-7763.

Sun X.L. and Ghosh U. (2008) The effect of activated carbon on partitioning, desorption, and biouptake of native polychlorinated biphenyls in four freshwater sediments, Environ. Toxicol. Chem., 27(11), 2287-2295.

Walters R.W. and Luthy R.G. (1984) Equilibrium adsorption of polycyclic aromatic hydrocarbons from water onto activated carbon, Environ. Sci. Technol., 18(6), 395-403.

Werner D., Higgins C.P. and Luthy R.G. (2005) The sequestration of PCBs in Lake Hartwell sediment with activated carbon, Water Research, 39(10), 2105-2113.

Werner D., Ghosh U. and Luthy R.G. (2006) Modeling polychlorinated biphenyl mass transfer after amendment of contaminated sediment with activated carbon, Environ. Sci. Technol., 40(13), 4211-4218.

Zimmerman J.R., Ghosh U., Millward R.N., Bridges T.S. and Luthy R.G. (2004) Addition of carbon sorbents to reduce PCB and PAH bioavailability in marine sediments: Physicochemical tests, Environ. Sci. Technol., 38(20), 5458-5464. 